\title{
The effect of heparin after primary percutaneous coronary intervention on short-term clinical outcomes in patients with ST-segment elevation myocardial infarction
}

\author{
Mohammed Rouzbahani, Mohsen Rezaie, Nahid Salehi, Parisa Janjani, \\ Reza Heidari Moghadam, Alireza Rai, Nafiseh Montazeri, Arsalan Naderipour, \\ Etrat Javadi Rad, Nader Asgari, Sousan Mahmoudi, Sayeh Motevaseli, Javad Azimivaghar*
}

Cardiovascular Research Center, Health Institute, Kermanshah University of Medical Sciences, Kermanshah, Iran

Received: 13 August 2020

Revised: 11 October 2020

Accepted: 12 October 2020

\section{*Correspondence:}

Dr. Javad Azimivaghar,

Email: babakhanymaryam@gmail.com

Copyright: () the author(s), publisher and licensee Medip Academy. This is an open-access article distributed under the terms of the Creative Commons Attribution Non-Commercial License, which permits unrestricted non-commercial use, distribution, and reproduction in any medium, provided the original work is properly cited.

\begin{abstract}
Background: Doing percutaneous coronary intervention (PCI) in the first hours of myocardial infraction (MI) is effective in re-establishment of blood flow. Anticoagulation treatment should be prescribed in patients undergoing PCI to decrease the side effects of ischemia. The aim of this study is to determine the effect of heparin prescription after PCI on short-term clinical outcomes in patients with ST-segment elevation myocardial infarction (STEMI).

Materials: This randomized clinical trial study was conducted at Imam Ali cardiovascular center at Kermanshah university of medical science (KUMS), Iran. Between April 2019 to October 2019, 400 patients with STEMI which candidate to PCI were enrolled. Patients randomly divided in two groups: intervention group (received 5,000 units of heparin after PCI until first 24 hours, every 6 hours) and control group (did not receive heparin). Data were collected using a checklist developed based on the study's aims. Differences between groups were assessed using independent ttests and chi-square (or Fisher exact tests).

Result: Observed that, mean prothrombin time (PT) $(13.30 \pm 1.60$ vs. $12.21 \pm 1.15, \mathrm{p}<0.001)$ and partial thromboplastin time $(\mathrm{PTT})(35.30 \pm 3.08$ vs. $34.41 \pm 3.01, \mathrm{p}=0.003)$ were significantly higher in intervention group compared to control group. Thrombolysis in myocardial infarction (TIMI) flow grade $0 / 1$ after primary PCI was significantly more frequently in control group (5.5\% vs. $1.0 \%, \mathrm{p}=0.034)$. The mean of ejection fraction (EF) after PCI (47.58 \pm 7.12 vs. $45.15 \pm 6.98, \mathrm{p}<0.001)$ was significantly higher in intervention group. Intervention group had a statistically significant shorter length of hospital stay $(4.71 \pm 1.03$ vs. $6.12 \pm 1.10, \mathrm{p}<0.001)$. There was higher incidence of re-vascularization $(0 \%$ vs. $3.0 \% ; \mathrm{p}=0.013)$ and re-MI $(0 \%$ vs. $2.5 \% ; \mathrm{p}=0.024)$ in the control group.

Conclusion: Performing primary PCI with receiving heparin led to improve TIMI flow and consequently better EF. Receiving heparin is associated with lower risk of re-MI and re-vascularization.
\end{abstract}

Keywords: MI, PCI, Outcome, Iran, Heparin

\section{INTRODUCTION}

Coronary artery disease (CAD), as costly condition, is the leading cause of death and disability worldwide. ${ }^{1,2}$ CAD directly is responsible for $12.2 \%$ of cardiovascular deaths. Acute coronary syndrome (ACS) has the most importance in $\mathrm{CAD}$ patients due to the high possibility of undesirable cardiovascular events in these patients. Generally, ACS includes unstable angina (UA), MI with and without elevating ST part (STEMI and NSTEMI). ${ }^{3}$

Among ACS patients, STEMI needs more urgent intervention and reperfusion to prevent ischemia and myocardial necrosis and restore the myocardial function. 
Appropriate reperfusion is done using thrombolysis or primary PCI. PCI can protect the left ventricle, reduce the infract size, and improve the long- term and short-term outcomes of disease. ${ }^{4,5}$ Doing PCI in the first hours of MI is effective in re-establishment of blood flow. Nowadays, improving reperfusion method has significantly decreased the rate of in-hospital death of STEMI; currently it is about $6 \%$ to $14 \% .^{6,7}$

Anticoagulation treatment should be prescribed in patients undergoing PCI to decrease the side effects of ischemia. Although, this treatment may excess the risk of bleeding that is related with in-hospital and late side effects. Despite the known disadvantages of heparin, it is the most common anticoagulant that used during PCI. ${ }^{8}$ The main aim of treatment with anticoagulation is protecting the infracted artery. Other aims include reducing thrombosis, wall coagulation (coagulation in heart), and deep vein thrombosis.

The aim of this study was to determine the effect of heparin prescription after PCI on short-term clinical outcomes in patients with STEMI.

\section{METHODS}

\section{Study population and design}

This randomized clinical trial study was conducted in Imam Ali cardiovascular center, KUMS, Iran. Imam Ali hospital is the main cardiovascular center in Western Iran. This public hospital with 280 active beds presents care services in cardiovascular field. Imam Ali hospital annually covers more than two million population mostly Kurdish with Caucasian race.

Between April 2019 to October 2019, 400 patients with STEMI which candidate to PCI were enrolled. The exclusion criteria included: age $\leq 18$ years of old, active bleeding, thrombocytopenia history with heparin, history of CABG or PCI, receiving heparin before hospitalization, and also, they did not formally consent to participate were excluded.

Patients randomly divided in two groups: intervention group (received 5,000 units of heparin after PCI until first 24 hours, every 6 hours) and control group (did not receive heparin).

\section{Data collection}

The demographic data, clinical histories, risk factors, and laboratory and angiographic findings of all consecutive patients were recorded by a nurse, using checklist developed based on study's objectives. Short-term clinical results (in-hospital and 1 month after PCI) included: hematoma, bleeding, major cardiac and cerebrovascular events (MACCEs), and EF was recorded using a checklist and compared in two groups. All checklists were checked and approved by a physician as responsible for quality control.

\section{Statistical methods}

Data analysis was done using statistical package for social sciences (SPSS) statistical software (version 23.0; IBM Corporation, Chicago, USA). Quantitative variables (e.g., age) were described using mean \pm standard deviation (SD) and qualitative/categorical variables (e.g., smoking) expressed as frequencies and percentages. Differences between groups were assessed using the chisquare (or Fisher exact tests) for categorical variables, and independent t-tests for continuous and normally distributed variables. The effect size scores were calculated for better comparing the differences between groups, using Cohen's d for continuous variables and chisquare (or Fisher exact tests) value for qualitative/categorical variables. Cohen's d was calculated by the difference in the means of the two groups divided by the weighted pooled standard deviations of these groups. All analyses were considered significant at $\mathrm{p}<0.05$.

\section{Ethical approval}

The research ethics committee at KUMS has approved the study protocol and has monitored the research process. Further, the participants had been given the participant information statement and had signed the written consent form. The individual personal information has been kept confidentially with access limited to researcher.

\section{RESULTS}

The demographic and clinical characteristics of patients are reported in (Table 1). The mean age of the intervention group was $60.47 \pm 11.16$ years old, and for control group, it was $61.30 \pm 12.14$ years old $(\mathrm{p}=0.477)$. TIMI flow grade $0 / 1$ after primary PCI was significantly more frequently in control group (5.5 vs. $1.0 \%, \mathrm{p}=0.034)$. Observed that, mean prothrombin time (PT) $(13.30 \pm 1.60$ vs. $12.21 \pm 1.15, \mathrm{p}<0.001)$ and PTT $(35.30 \pm 3.08$ vs. $34.41 \pm 3.01, \quad \mathrm{p}=0.003)$ were significantly higher in intervention group compared to control group. The mean of second EF (after PCI) (47.58 \pm 7.12 vs. 45.15 \pm 6.98 , $\mathrm{p}<0.001$ ) was significantly higher in intervention group compared to control group. Intervention group had a statistically significant shorter length of hospital stay (4.71 \pm 1.03 vs. $6.12 \pm 1.10, \mathrm{p}<0.001)$.

The bleeding, death, hematoma, and stroke were not significantly different in the heparin group compared with the control group. There was higher incidence of revascularization $(0 \%$ vs. $3.0 \% ; \mathrm{p}=0.013)$ and re-MI $(0 \%$ vs. $2.5 \%$; $=0.024$ ) in the group of patients who did not receive heparin. 
Table 1: Baseline characteristics of the patients $(n=400)$.

\begin{tabular}{|c|c|c|c|}
\hline Characteristics & Intervention group $(n=200)$ & Control group $(n=200)$ & 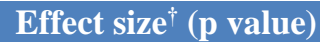 \\
\hline Age $(\text { years) })^{\text {II }}$ & $60.47 \pm 11.16$ & $61.30 \pm 12.14$ & $0.071(0.477)^{*}$ \\
\hline BMI $\left(\mathrm{kg} / \mathrm{m}^{2}\right)^{\text {II }}$ & $26.84 \pm 3.11$ & $26.46 \pm 3.38$ & $0.117(0.242)^{*}$ \\
\hline Male & $131(65.5)$ & $127(63.5)$ & $0.175(0.675)^{* *}$ \\
\hline Current smoker & $64(32.0)$ & $69(34.5)$ & $0.282(0.595)^{* *}$ \\
\hline Diabetes mellitus & $70(35.0)$ & $73(36.5)$ & $0.098(0.754)^{* *}$ \\
\hline Hypertension & $107(53.5)$ & $100(50.0)$ & $0.491(0.483)^{* *}$ \\
\hline Hypercholesterolemia & $87(43.5)$ & $91(45.5)$ & $0.162(0.687)^{* *}$ \\
\hline Chronic kidney disease & $3(1.5)$ & $5(2.5)$ & $0.510(0.475)^{* * *}$ \\
\hline Liver disease & $1(0.5)$ & $1(0.5)$ & $0(1)^{* *}$ \\
\hline COPD & $3(1.5)$ & $3(1.5)$ & $0(1)^{* * *}$ \\
\hline \multicolumn{4}{|l|}{ No. of culprit vessels } \\
\hline 1 -vessel & $64(32.0)$ & $62(31.0)$ & \multirow{3}{*}{$0.060(0.970)^{* *}$} \\
\hline 2-vessel & $67(33.5)$ & $67(33.5)$ & \\
\hline 3-vessel & $69(34.5)$ & $71(35.5)$ & \\
\hline \multicolumn{4}{|l|}{ Culprit vessel } \\
\hline LAD & $108(54.0)$ & $103(51.5)$ & \multirow{4}{*}{$1.044(0.790)^{* *}$} \\
\hline LMS & $4(2.0)$ & $2(1.0)$ & \\
\hline LCX & $26(13.0)$ & $28(14.0)$ & \\
\hline $\mathrm{RCA}$ & $65(32.5)$ & $70(35.0)$ & \\
\hline \multicolumn{4}{|l|}{ Pre-procedural TIMI flow } \\
\hline TIMI flow grade $0 / 1$ & $180(90.0)$ & $181(90.5)$ & \multirow{3}{*}{$0.336(0.845)^{* *}$} \\
\hline TIMI flow grade 2 & $18(9.0)$ & $18(9.0)$ & \\
\hline TIMI flow grade 3 & $2(1.0)$ & $1(0.5)$ & \\
\hline \multicolumn{4}{|c|}{ Post-procedural TIMI flow } \\
\hline TIMI flow grade $0 / 1$ & $2(1.0)$ & $11(5.5)$ & \multirow{3}{*}{$6.72(0.034)^{* *}$} \\
\hline TIMI flow grade 2 & $12(6.0)$ & $14(7.0)$ & \\
\hline TIMI flow grade 3 & $186(93.0)$ & $175(87.5)$ & \\
\hline First EF (before PCI) ${ }^{q}$ & $41.85 \pm 6.33$ & $42.15 \pm 7.64$ & $0.042(0.669)^{*}$ \\
\hline Second EF (after PCI) ${ }^{\mathbb{I I}}$ & $47.58 \pm 7.12$ & $45.15 \pm 6.98$ & $0.344(<0.001)^{*}$ \\
\hline Length of stay (days) ${ }^{\mathbb{I}}$ & $4.71 \pm 1.03$ & $6.12 \pm 1.10$ & $1.323(<0.001)^{*}$ \\
\hline PT $^{\text {II }}$ & $13.30 \pm 1.60$ & $12.21 \pm 1.15$ & $0.782(<0.001)^{*}$ \\
\hline PTT $^{\mathrm{II}}$ & $35.30 \pm 3.08$ & $34.41 \pm 3.01$ & $0.292(0.003)^{*}$ \\
\hline INR $^{\mathbb{I}}$ & $1.01 \pm 0.09$ & $0.91 \pm 0.08$ & $1.174(0.999)^{*}$ \\
\hline
\end{tabular}

Table 2: Short-term clinical outcomes in patients undergoing PCI $(n=400)$.

\begin{tabular}{|llll|}
\hline Characteristics & Intervention group $(\mathbf{n = 2 0 0 )}$ & Control group $(\mathbf{n = 2 0 0})$ & Effect size $^{*}(\mathbf{p}$ value) \\
\hline Bleeding & $3(1.5)$ & $1(0.5)$ & $1.013(0.314)^{* *}$ \\
\hline Hematoma & $4(2.0)$ & $1(0.5)$ & $1.823(0.176)^{* *}$ \\
\hline Stroke & $0(0)$ & $0(0)$ & $0(1)^{* *}$ \\
\hline Re-MI & $0(0)$ & $5(2.5)$ & $5.063(0.024)^{* *}$ \\
\hline Re-vascularization & $0(0)$ & $6(3.0)$ & $6.091(0.013)^{* *}$ \\
\hline Death & $0(0)$ & $3(1.5)$ & $3.023(0.082)^{* *}$ \\
\hline
\end{tabular}

N-Number, MI- Myocardial Infarction. $†$ The effect size scores were reported using Cohen's $d$ for continuous variables and chi-square (or Fisher exact tests) value for qualitative/categorical variables.** chi-square.

\section{DISCUSSION}

This randomized clinical trial study aimed to determine effect of heparin on short-term clinical outcomes in STEMI patients who undergoing PCI at Imam Ali cardiovascular center at KUMS between April and October 2019.

\section{Comparison of this results with other studies}

There was no significant difference between intervention and control groups in term of variables as age, sex and etc. However, there was significant difference between PTT and PT in both intervention and control groups. PT and PTT level was significantly higher in heparin users 
compared to control group. Actually, anticoagulant drugs like heparin increase the level of PT and PTT.

The results demonstrated that following the angioplasty treatment of patients, generally EF has increased. Although, EF has significantly improved in intervention group compared to control group. In line with findings, Zamani's survey in Iran, Ardabil, reported that EF has improved in patients who received heparin comparing control group. ${ }^{9}$ Zijlstra et al reported that patients who received pre hospital heparin significantly had higher EF. ${ }^{10}$ Verheugt et al observed that early therapy with heparin resulted in full coronary reperfusion in a significant number of MI patients. ${ }^{11}$

This study showed that $0-1$ TIMI flow after PCI significantly in control group was more than intervention group $(5.5 \%$ versus $1.0 \%)$ however, before PCI there was no significant difference between two groups $(90.0 \%$ versus $90.5 \%$ ). Illustrating that post-procedural TIMI flow in heparin group was higher than control group which be with higher angioplasty success. In consistent with the result, Zijlstra et al, reported that TIMI score in heparin group was higher than control group. ${ }^{10}$ Also, Chung et al. observed that 2/3 TIMI scores was higher in heparin-receiving groups. ${ }^{12}$ Conversely, Zamani and colleagues demonstrated that there were no differences between TIMI scores in two groups. ${ }^{9}$

Four major bleeding occurred in the current study, 3 $(1.5 \%)$ in the heparin group and $1(0.5 \%)$ in the control group, which is not significantly higher than previous studies that heparin be prescribed with PCI. ${ }^{10-14}$ Of these 4 patients, all experienced profuse bleeding in the tracheostomy site, and 2 patients required a blood transfusion after PCI. Stone et al reported that, in heparin group, the major bleeding is occurred in $8.3 \%$ patients which was more than results. ${ }^{15}$

Found that the rate of hematoma was higher in intervention group comparing the control group but not meaningful. The results concur with the findings of previous studies. Zamani and colleagues reported that in case group compared to control group the rate of hematoma was higher but not significant. ${ }^{9}$ Plus, Bonello's survey in USA, with a similar design as ours, found that the incidence rate of Hematoma in heparin group was more than control group. ${ }^{16}$

The findings of this study showed that the control group had more 30-day death compared to intervention group but difference was not statistically significant $(1.5 \%$ vs. $0 \%)$. Likewise, Steg et al found that there was no significant difference of death rate between heparin receiving and control group. ${ }^{17}$ Furthermore, Zamani and assistants reported that the heparin group had more 30day mortality than control group but not meaningful. ${ }^{9}$ Jovin et al demonstrated that the heparin group had more death than control group, significantly. ${ }^{18}$ Zijlstra et al showed that heparin group comparing control group had lower 30-day death rate. ${ }^{10}$ Stone et al have reported that rate of death for heparin group was $3.1 \%$; plus, Bonello et al found that the rate of death for heparin group was $1.1 \%$, which was more than this result. ${ }^{15,18}$

Besides, found that the control group was more likely to experience the re-MI and need re-vascularization, significantly. Jovin et al showed that no significant difference in the rate of re-MI between heparin group and bivalirudin group. ${ }^{18}$ Observed that heparin group significantly had a shorter length of hospital stay compared to control group. In contrast, Jovin et al reported that heparin group had a slightly but statistically significant longer length of hospital stays. ${ }^{18}$ The differences between the results of this study and previous studies may be due to difference in the sample size, risk factors, angiographic characteristics and the time of receiving treatment.

\section{CONCLUSION}

This study found that, generally, performing primary PCI with receiving heparin in STEMI patients led to improve blood flow in clogged artery and TIMI flow. Receiving Heparin led to better EF and finally a better function of left ventricle. Receiving heparin is associated with lower risk of 30-days mortality, re-MI and re-vascularization.

\section{ACKNOWLEDGEMENTS}

Author would like to thank the Kermanshah university of medical sciences for funding this project. Also, greatly appreciate Kermanshah Imam Ali cardiovascular center. Also, thank to willing and helpful participants.

\section{Funding: No funding sources}

Conflict of interest: None declared

Ethical approval: The study was approved by the Institutional Ethics Committee

\section{REFERENCES}

1. Pieris RR, Al-Sabti HA, Al-Abri QSA, Rizvi SGA. Prevalence pattern of risk factors for coronary artery disease among patients presenting for coronary artery bypass grafting in Oman. Oman medi J. 2014;29:203.

2. Shyu K-G, Wu C-J, Mar G-Y, Hou CJ-Y, Li A-H, Wen M-S et al. Clinical characteristics, management and in-hospital outcomes of patients with acute coronary syndromed observations from the Taiwan ACS full spectrum registry. Acta Cardiol Sin. 2011;27:e44 .

3. Danese E, Montagnana M. An historical approach to the diagnostic biomarkers of acute coronary syndrome. Ann translational med. 2016;4(10)194.

4. Beig JR, Tramboo NA, Kumar K, Yaqoob I, Hafeez I, Rather FA, et al. Components and determinants of therapeutic delay in patients with acute ST-elevation 
myocardial infarction: A tertiary care hospital-based study. J Saudi Heart Asso. 2017;29:7-14 .

5. Windecker S, Hernández-Antolín R-A, Stefanini GG, Wijns W, Zamorano JL. Management of STelevation myocardial infarction according to European and American guidelines. EuroIntervention: journal of EuroPCR in collaboration with the Working Group on Interventional Cardiology of the European Society of Cardiology. Eu Society Cardiol. 2014;10:T23-31.

6. O'Gara PT, Kushner FG, Ascheim DD, Casey DE, Chung MK, De Lemos JA et al. 2013 ACCF/AHA guideline for the management of ST-elevation myocardial infarction: a report of the American College of Cardiology Foundation/American Heart Association Task Force on Practice Guidelines. J Am college cardiol. 2013;61:e78-e140 .

7. Guillermin A, Yan DJ, Perrier A, Marti C. Safety and efficacy of tenecteplase versus alteplase in acute coronary syndrome: a systematic review and metaanalysis of randomized trials. Arch med sci. 2016;12:1181.

8. Briguori C, Visconti G, Focaccio A, Donahue M, Golia B, Selvetella L et al. Novel approaches for preventing or limiting events (Naples) III trial: randomized comparison of bivalirudin versus unfractionated heparin in patients at increased risk of bleeding undergoing transfemoral elective coronary stenting. JACC. Cardiovasc Interv. 2015;8:414-23.

9. Zamani B, Abdollahi A, Mardi A. The effect of heparin prescription before primary PCI on longterm and short-term clinical and para clinical results and the mortality of patients with acute coronary syndrome. Int J Basic Clin Pharmacol. 2018;7:74852.

10. Zijlstra F, Ernst N, de Boer M-J, Nibbering E, Suryapranata $\mathrm{H}$, Hoorntje JC et al. Influence of prehospital administration of aspirin and heparin on initial patency of the infarct-related artery in patients with acute ST elevation myocardial infarction. J Am College of Cardiol. 2002;39:1733-7.

11. Verheugt FW, Liem A, Zijlstra F, Marsh RC, Veen G, Bronzwaer JG. High dose bolus heparin as initial therapy before primary angioplasty for acute myocardial infarction: results of the Heparin in Early Patency (HEAP) pilot study. J Am College Cardiol. 1998;31:289-93.
12. Chung W-Y, Han M-J, Cho Y-S, Kim K-I, Chang HJ, Youn T-J et al. Effects of the early administration of heparin in patients with ST-elevation myocardial infarction treated by primary angioplasty. Circulation J. 2007;7(1):862-7.

13. Liem A, Zijlstra F, Ottervanger JP, Hoorntje JC, Suryapranata H, de Boer M-J et al. High dose heparin as pretreatment for primary angioplasty in acute myocardial infarction: the Heparin in Early Patency (HEAP) randomized trial. J Am College Cardiol. 2000;35:600-4.

14. Labèque JN, Jaïs C, Dubos O, Denard M, Berhouet M, Leroux L et al. Prehospital administration of enoxaparin before primary angioplasty for STelevation acute myocardial infarction. Catheter cardiovas interven. 2006;67:207-13.

15. Stone GW, Witzenbichler B, Guagliumi G, Peruga JZ, Brodie BR, Dudek D et al. Bivalirudin during primary PCI in acute myocardial infarction. $\mathrm{N}$ Eng $\mathrm{J}$ Med. 2008;358:2218-30.

16. Bonello L, De Labriolle A, Roy P, Steinberg DH, Slottow TLP, Xue Z et al. Head-to-head comparison of bivalirudin versus heparin without glycoprotein IIb/IIIa inhibitors in patients with acute myocardial infarction undergoing primary angioplasty. Cardiovasc Revascul Med. 2009;10:156-61.

17. Steg PG, Van't Hof A, Hamm CW, Clemmensen P, Lapostolle F, Coste P et al. Bivalirudin started during emergency transport for primary PCI. N Engl J Med. 2013;369:2207-17.

18. Jovin IS, Shah RM, Patel DB, Rao SV, Baklanov DV, Moussa I et al. Outcomes in patients undergoing primary percutaneous coronary intervention for STsegment elevation myocardial infarction via radial access anticoagulated with bivalirudin versus heparin: a report from the National Cardiovascular Data Registry. JACC: Cardiovasc Interv. 2017;10:1102-11

Cite this article as: Rouzbahani M, Rezaie M, Salehi N, Janjani P, Moghadam RH, Rai A, et al. The effect of heparin after primary percutaneous coronary intervention on short-term clinical outcomes in patients with ST-segment elevation myocardial infarction. Int J Basic Clin Pharmacol 2020;9:1636-40. 